\title{
Diabetic Peripheral Neuropathy: Epidemiology, Physiopathology, Diagnosis and Treatment
}

\author{
Nazma Akter ${ }^{1}$
}

\begin{abstract}
Diabetic peripheral neuropathy (DPN) is a common complication of both type 1 and type 2 diabetes. It affects over $90 \%$ of the diabetic patients. It is widely accepted that the toxic effects of hyperglycemia play an important role in the development of this complication, but several other hypotheses have been postulated. It is typically characterized by significant deficits in tactile sensitivity, vibration sense, lower-limb proprioception, and kinesthesia. Painful DPN has been shown to be associated with significant reductions in overall quality of life, increased levels of anxiety and depression, sleep impairment, and greater gait variability. DPN is often misdiagnosed and inadequately treated. Clinical recognition of DPN is imperative for allowing timely symptom management to reduce the morbidity associated with this condition. The management of diabetic neuropathic pain consists basically in excluding other causes of painful peripheral neuropathy, improving glycemic control as a prophylactic therapy and using medications to alleviate pain. First line drugs for pain relief include anticonvulsants, such as pregabalin and gabapentin and antidepressants, especially those that act to inhibit the reuptake of serotonin and noradrenaline. In addition, there is experimental and clinical evidence that opioids can be helpful in pain control, mainly if associated with first line drugs. Other agents, including for topical application, such as capsaicin cream and lidocaine patches, have also been proposed to be useful as adjuvant in the control of diabetic neuropathic pain, but the clinical evidence is insufficient to support their use. The purpose of this review is to examine proposed mechanisms of DPN, summarize current treatment regimen. A better understanding of the mechanisms underlying diabetic neuropathic pain will contribute to the search of new therapies.
\end{abstract}

\section{Methodology}

A comprehensive literature review was undertaken, incorporating article searches in electronic databases (EMBASE, PubMed, and OVID) and reference lists of relevant articles with the authors' expertise in DPN. This review considers seminal and novel research in epidemiology; diagnosis, and the treatment of neuropathic pain in DPN.

Keywords: Diabetes; Neuropathic pain; Diabetic peripheral neuropathy ;Diagnosis; Epidemiology; Pharmacotherapy; Anticonvulsants; Antidepressants

$$
\text { Delta Med Col J. Jan 2019;7(1):35 - } 48
$$

1. Assistant Professor (Endocrinology \& Metabolism), Dept. of Medicine, MARKS Medical College \& Hospital, Mirpur, Dhaka, Bangladesh.

Correspondence: Dr. Nazma Akter. e-mail: nazma_aktar_endo@yahoo.com 


\section{Introduction}

Diabetes has reached epidemic proportions worldwide, with International Diabetes Federation estimates suggesting a prevalence of 425 million people worldwide in 2017, rising to 628 million by $2045 .{ }^{1}$ This rise will be accompanied by an increase in the prevalence of the complications of diabetes. $^{2}$ Diabetic peripheral neuropathy (DPN) is the most common cause of neuropathy worldwide, and is estimated to affect around half of people with diabetes. ${ }^{3,4}$ It causes considerable morbidity, impairs quality of life, and increases mortality. 5,6 Generally, DPN affects the toes and distal foot, but slowly progresses proximally to involve the feet and legs in a stocking distribution. It is also characterized by a progressive loss of nerve fibers affecting both the autonomic and somatic divisions, thereby diabetic retinopathy and nephropathy can occur. ${ }^{7}$ Foot ulceration and painful neuropathy are the main clinical consequences of DPN, linked with higher morbidity and mortality. ${ }^{8}$ Frequently, patients look for medical help only when pain appears ${ }^{9}$, a symptom that affects $10 \%$ to $26 \%$ of this population. ${ }^{10}$ Diabetic neuropathic pain (DNP) is characterized by tingling, burning, sharp, shooting, and lancinating or even as electric shock sensations. ${ }^{7}$ It is usually considered moderate to severe and often worse at night, causing sleeping disturbs. The pain can be constant and accompanied of cutaneous allodynia, which can substantially affect the quality of life of patients, impacting the ability to perform daily activities and having a negative influence on mood. The pain may also be a reason of withdrawal of recreational and social activities and may be associated with depression.7,11,12 The pathogenesis of DNP is not fully understood. Several theories have been proposed to explain the pain related to the diabetic neuropathy, such as changes in the blood vessels that supply the peripheral nerves; metabolic and autoimmune disorders accompanied by glial cell activation, changes in sodium and calcium channels expression and more recently, central pain mechanisms, such as increased thalamic vascularity and imbalance of the facilitatory/ inhibitory descendingpathways. ${ }^{7}$ Additionally, several risk factors are associated with DNP including worsening glucose tolerance, older age, longer diabetes duration, drinking alcohol and cigarette smoking. ${ }^{12}$ Currently, only three agents are approved by most of the guidelines for the treatment of DNP: duloxetine, a selective serotonin and norepinephrine reuptake inhibitor, pregabalin, an anticonvulsant, and the dual effect drug tapentadol, an opioid receptor agonist and norepinephrine reuptake inhibitor. ${ }^{13}$ However, aspain relief is unsatisfactory for most patients, several pharmacological interventions have been used based on pre-clinical and/or clinical evidence, as well as an inference of mechanism of action. Despite the considerable, health care related economic burden and defect on quality of life in DPN, treatment options are limited and prevention remains the key goal. ${ }^{14}$ The purpose of this review was to critically review the current literature on the diagnosis and treatment of DPN, with a focus on the treatment of neuropathic pain in DPN.

\section{Epidemiology}

Epidemiologic studies of diabetic neuropathy have provided heterogeneous results, owing to different patient populations, definitions of neuropathy used, and methods of assessments. Pre diabetes is also associated with neuropathy. ${ }^{15}$ In a Spanish study, the reported prevalence of DPN in primary care was $21 \%$ compared to $2.7 \%$ in-hospital. ${ }^{16}$ In the San Luis Valley cohort, ${ }^{17}$ the prevalence of peripheral neuropathy in patients with diabetes was $25.8 \%$, as compared to $11.2 \%$ in subjects with impaired glucose tolerance (IGT) and $3.9 \%$ in control subjects. The Rochester Neuropathy Study ${ }^{16}$ evaluated data from 380 participants; where DPN, diagnosed using a multifaceted approach, including the neuropathy symptom score, neuropathy disability score, and nerve conduction studies, was found in $66 \%$ and $59 \%$ of patients with type 1 and 2 diabetes, respectively. Importantly, approximately $10 \%$ of 
participants had a non diabetic etiology of the neuropathy. ${ }^{16} \mathrm{~A}$ community based study in about 15,000 patients with diabetes showed that $34 \%$ of patients had symptoms of painful neuropathy, with an increased risk in patients with type 2 diabetes, women, and people of South Asian origin. ${ }^{18}$ The prevalence of DPN is considered to be low in patients with early type 1 diabetes; however, among participants in the Diabetes Control and Complications Trial (DCCT), the prevalence of abnormal neurologic exam results were almost $20 \%$ in those on conventional treatment and almost $10 \%$ in those on intensive treatment, after 5years of follow up. ${ }^{19}$ In the EURODIAB IDDM complications study, ${ }^{20}$ which evaluated over 3000 patients across 16 countries, there was a $28 \%$ baseline neuropathy prevalence, which rose by $23.5 \%$ after 7 years. The risk factors for the development of neuropathy included age, duration of diabetes, poor glycemic control, elevated low-density lipoprotein cholesterol and triglycerides, hypertension, obesity, and smoking. ${ }^{20}$ The EDIC (Epidemiology of Diabetes Interventions and Complications) study, following up patients up for 13 years after the initial 6.5 years of the DCCT, showed an initial $64 \%$ reduction in the risk for DPN in those on intensive compared to conventional treatment during the DCCT period and a $30 \%$ risk reduction was maintained in the follow-up EDIC studyperiod. ${ }^{21}$

\section{Physiopathology of neuropathic pain in diabetes}

Although there is a great advance in understanding the pathophysiological mechanisms leading to the development of diabetic complications, there is not yet a plausible hypothesis to explain why some patients develop the painful form of disease while others do not. However, interestingly, pain intensity normally is not associated with neuropathy severity, and can occur even in the absence of nerve injuries. ${ }^{22,23}$ The exact mechanism by which diabetes causes neuropathy has not been clearly elucidated, but increased levels of advanced glycation end products (AGE) and protein kinase $\mathrm{C}$ (PKC) due to prolonged hyperglycemia are thought to be involved in peripheral nerve damage. Oxidative stress caused by AGE creates microscopic vascular damages, hindering blood supply to the peripheral nerves. ${ }^{24}$ Certain proinflammatory cytokines including IL-6 and TNF- $\alpha$, are also elevated during hyperglycemia and are thought to contribute to nerve cell damage. ${ }^{25}$ Based on these mechanisms, treating diabetic neuropathy using molecular chaperones including certain heat shock proteins (HSP) to prevent nerve injuries may be a viable option. ${ }^{25}$ While nerve damage from hyperglycemia is a common pathophysiology shared by both the non painful neuropathy and painful neuropathy in diabetes, painful presentations of diabetic neuropathy appear to stem from the body's over compensations or abnormal responses to the nerve damage. A cascade of events following the nerve damage leads to abnormal expression of sodium channels along the axon at the site of peripheral nerve damage, leading to ectopic neural discharge. ${ }^{26}$ There is an altered expression of $\mathrm{Na}^{+}, \mathrm{K}^{+}$, and $\mathrm{Ca}^{2+}$ channels in the nociceptive neurons of the dorsal root ganglion, as well as abnormal proliferation and sprouting of sympathetic neurons. The result of these events is exaggerated or spontaneous pain sensation. ${ }^{26}$ Hemodynamic factors have been suggested to be distinct between the non-painful versus the painful phenotypes, as epineurial intravascular oxygen saturation and blood flow were shown to be higher in people with painful neuropathy, possibly as a result of arteriovenous shunting and consequent endoneurium hypoxia stimulating painful sensation. ${ }^{27}$ Recent studies have also implicated involvements of central pain processing mechanisms in painful DPN, showing that aberrant neurons in the ventral posterolateral thalamus of diabetes patients could become hyper-excitable and amplify the painful sensation. ${ }^{28}$ This central process may be related to elevated thalamic perfusion or abnormal supraspinal modulation of sensory processing arising potentially due to damage from prolonged hyperglycemia, generating allodynia and hyperalgesia. ${ }^{29,30}$ Presence of a possible genetic 
component in painful DPN has also been suggested. ${ }^{31}$ For instance, mutations in certain genes coding for tetrahydrobiopterin (BH4) may increase susceptibility to painful neuropathy. ${ }^{32}$ DPN is significantly more common in type 2 than in type 1 diabetes. ${ }^{33}$ Pain tends to be bilateral and although it predominantly involves lower limbs, specifically the foot, in some cases, upper extremities may be involved, including fingertips and palms. ${ }^{34}$ This distribution pattern occurs because the longest sensory axons are usually the first to be affected by diabetes. ${ }^{24}$ Patients typically describe their neuropathic pain by using words such as "hot", "burning", "electric", “jolts", "sharp", "tingling", and "pins and needles". ${ }^{31}$ It may also be accompanied by allodynia (painful response to normally non-painful stimuli) and hyper algesia (exaggerated response to mild pain stimuli). Pain is often worse during the night, as well as under stress and fatigue. ${ }^{31}$ Painful DPN poses a substantial and growing concern for patients and the health care system. DPN has been shown to be associated with significant reductions in overall quality of life in a cross-sectional study, where patients with painful DPN showed significantly poorer quality of life compared to those without neuropathy and those with non-neuropathic pain. ${ }^{35}$ Painful neuropathy also causes considerable disability, with one-third of patients requiring a walking assist device such as a cane, walker, or wheel chair due to their neuropathy. ${ }^{31} \mathrm{~A}$ study investigating gait function in type 2 diabetes mellitus patients with DPN found significantly greater gait variability and higher number of self-reported falls in DPN patients with painful neuropathy than in DPN patients without painful neuropathy, suggesting that pain by itself affects walking ability. ${ }^{36}$ The severity of painful DPN is associated with increasing levels of anxiety and depression, as well as significant sleep impairment. ${ }^{37}$

\section{Diagnosis of DPN}

The American Diabetes Association's position statement on diabetic neuropathy 2017 advises that the early recognition of neuropathy and initiation of appropriate management are essential to the management of patients with diabetes. ${ }^{38}$ Alternative etiologies of neuropathy should be actively diagnosed and treated. These include chronic inflammatory demyelinating polyneuropathy, $\mathrm{B}_{12}$ deficiency, hypothyroidism, and uremia, which may concomitantly occur in diabetes. ${ }^{39}$ The tests frequently used to diagnose DPN have been listed in Table I, along with their advantages and disadvantages and type of nerve fiber they assess. ${ }^{39}$

Table I: A summary of the common tests used to assess neuropathy

\begin{tabular}{|c|c|c|c|}
\hline Test & Advantage & Disadvantage & Type of Nerve \\
\hline NCS & $\begin{array}{l}\text { Sensitive, specific, } \\
\text { and reproducible } \\
\text { and easily } \\
\text { standardized gold } \\
\text { standard technique }\end{array}$ & $\begin{array}{l}\text { Must be done by trained } \\
\text { professional }\end{array}$ & Large fiber \\
\hline NDS & $\begin{array}{l}\text { Good predictor for } \\
\text { risk for ulceration }\end{array}$ & $\begin{array}{lll}\text { Does not detect } & \text { sub- } \\
\text { clinical } & \text { large } & \text { fiber } \\
\text { damage. } & & \\
\end{array}$ & Large and small fiber \\
\hline QST & $\begin{array}{l}\text { Reproducible and } \\
\text { reliable }\end{array}$ & Subjective & Large and small fiber \\
\hline $\begin{array}{l}\text { Skin } \\
\text { biopsy }\end{array}$ & $\begin{array}{lr}\text { Gold } & \text { Standard, } \\
\text { reliable } & \text { and } \\
\text { reproducible }\end{array}$ & $\begin{array}{l}\text { Invasive procedure. Needs } \\
\text { specialized laboratory } \\
\text { service }\end{array}$ & Small fiber \\
\hline $\mathrm{CCM}$ & $\begin{array}{l}\text { Rapid, } \\
\text { reproducible, } \\
\text { noninvasive. Can } \\
\text { detect small fiber } \\
\text { damage and track } \\
\text { progression }\end{array}$ & $\begin{array}{l}\text { Must be done by trained } \\
\text { professional. }\end{array}$ & Small fiber \\
\hline
\end{tabular}

\section{Screening}

Patients with type 2 diabetes mellitus should be screened annually from diagnosis, and those with type 1 diabetes, after 5 years of diagnosis. ${ }^{38}$ People with prediabetes should also undergo an assessment for neuropathy if symptoms arepresent. $^{38}$ Questionnaires is a subjective method to assess and quantify the severity of neuropathic symptoms and pain. The McGill Pain Questionnaire $^{40}$ is widely used to evaluate neuropathic pain.

\section{Assessment}

The assessment of patients for DPN should include a careful and focused history. 
Symptomology of neuropathy will differ according to the type of nerve fiber involvement. Patients with large fiber dysfunction may experience numbness, tingling, or poor balance. Small fiber neuropathy (SFN) may present with neuropathic pain described as burning, stabbing, or electric shocks. Pain is the trigger for patients to seek medical care in $25 \%$ of patients diagnosed with DPN. ${ }^{41,42}$

DPN is common, and the diagnosis of DPN begins with a careful history and examination of sensory and motor symptoms and signs. The quality and severity of neuropathic pain, if present, should be assessed using a validated method that is reproducible, such as the Michigan Neuropathy Screening Instrument. ${ }^{38}$ Examination within a clinic setting should include inspection of the feet and evaluation of reflexes and sensory responses to vibration, light touch, pinprick, and the $10 \mathrm{~g}$ monofilament. Many patients may be asymptomatic, and thus examination is the key to the diagnosis. A bedside test should be employed for both small and large fiber neuropathy, such as the neuropathy disability score (NDS), which is a validated reliable and reproducible screening tool that can also assess the severity of neuropathy. The NDS consists of testing sensory modalities, which include pain sensation (pinprick), temperature perception (using hot and cold rods), and vibration (128-Hz tuning fork), all scored as either normal (0) or reduced/absent (1). Abbott et al. ${ }^{43}$ showed that a neuropathy disability score of $46 / 10$ was an independent risk factor for new foot ulcers. All patients should undergo annual 10-g monofilament and pedal pulse evaluation to assess the risk for foot ulcers. ${ }^{38}$ The key is that the $10-\mathrm{g}$ monofilament should not be used to diagnose or exclude DPN as it detects only advanced neuropathy. Indeed, in a recent systematic review it was shown to have a very poor diagnostic utility, with a sensitivity of $88 \%$ but a specificity of only $55 \%$, when nerve conduction was used to diagnose DPN. ${ }^{44}$ The alternative 1-g monofilament may, however, be better for detecting earlier neuropathy. ${ }^{45}$ The assessment of Small Fiber Neuropathy (SFN) remains a particular challenge, especially in diabetic neuropathy. ${ }^{46}$
The exact pathophysiologic mechanisms of DPN remain to be elucidated, and treatments targeted at the natural history and pathophysiologic mechanisms of DPN are urgently required.

\section{Diagnostic definition}

The Toronto Diabetic Neuropathy Expert group ${ }^{42}$ classifies DPN as:

1. Confirmed DPN: abnormal nerve conduction and a symptom or sign of neuropathy;

2. Probable DPN: 2 or more of the following signs or symptoms - neuropathic symptoms, decreased distal sensation, or decreased/absent ankle reflexes; or

3. Possible DPN: any of the following symptoms: decreased sensation, positive neuropathic sensory symptoms (e.g. "asleep numbness," prickling/stabbing, burning, or aching pain), predominantly in the toes, feet, or legs; OR signs, including symmetric decrease of distal sensation or decreased/absent ankle reflexes.

The ADA's position statement does not recommend the use of neurophysiology for the diagnosis of typical DPN, and this testing modality should be reserved for patients in whom atypical features are present or the diagnosis is unclear.

\section{Management of painful diabetic neuropathy}

DNP continues to represent therapeutic challenges its pathophysiology is not yet fully understood and pain relief is still unsatisfactory. The pharmacological treatments, with exception to those targeted to the glycemic control, are symptomatic, not focused on the pathophysiological mechanisms, limited by side effects and by the development of tolerance. ${ }^{7,47}$

\section{Diet and lifestyle interventions}

In patients with IGT, lifestyle intervention could arrest the underlying process that leads to neuropathy. The Diabetes Prevention Program 
study 48 demonstrated that lifestyle changes and treatment with metformin reduced the prevalence of diabetes in those with IGT. Lifestyle intervention may also be effective in preventing DPN, as shown in the IGT Causes Neuropathy study ${ }^{49}$, in which diet and exercise counseling in subjects with IGT resulted in increased intra epidermal nerve fiber density (IENFD) and an improvement in neuropathic pain.

\section{Weight loss}

Experimental studies have shown that incretin-based therapies have valuable effects on diabetic complications, independent of their glucose-lowering abilities, mainly mediated by their anti inflammatory and anti oxidative stress properties. ${ }^{50}$ However, in a pilot study in patients with type 2 diabetes and mild to moderate DPN, 18 months of treatment with exenatide, compared with glargine, had no effect on neuropathy. ${ }^{51}$ In a meta-analysis of data from 10 studies, there was greater remission and lower risks for microvascular and macro vascular disease and mortality in the bariatric surgery group as compared to a non-surgical treatment group in patients with type 2 diabetes after at least 5 years of follow-up. ${ }^{52}$ In a study of bariatric surgery in patients with and without diabetes, there were improvements in body mass index, systemic inflammation, metabolic parameters, and small nerve fibers, as measured by corneal confocal microscopy (CCM). ${ }^{53}$ Micronutrient deficiencies after bariatric surgery are associated with an acute neuropathy ${ }^{54}$, and longer longitudinal studies that accurately phenotype neuropathy are required to delineate potential risk factors for this condition.

Exercise intervention in people with painful diabetic neuropathy

Physical exercise and a healthy diet have been shown to improve the management of diabetes and its complications ${ }^{55}$, although very few studies have investigated the effects of exercise on painful DPN. Multiple meta-analyses of randomized controlled trials ${ }^{56}$ and clinical studies ${ }^{57}$ suggest that exercise training of aerobic exercise, resistance training, or combined training is associated with reduction in $\mathrm{HbAlc}$ and improvement in functional capacity, strength, and glycemic control respectively. Exercise has also shown to have an effect on glycemic control in diabetes independent from weight control.58 Exercise training also improves cardiovascular complications of diabetes by ameliorating endothelial dysfunction and arterial remodeling and stiffness, likely via restoration of normal reduction oxidation balance. ${ }^{59}$ Improvement in skeletal muscle metabolism through the enhancement of certain mitochondrial content levels is another potential benefit of regular exercise training. ${ }^{60} \mathrm{On}$ the other hand, the effects of exercise training on quality of life, depression, and anxiety are inconclusive at this point, as the literature has shown mixed results and may require additional well-designed randomized controlled trials. ${ }^{61}$

Treatment of DPN The management of pain remains the key aspect of symptom treatment for DPN. A wide variety of drugs, used alone or in combination, has been shown to significantly reduce neuropathic pain compared with placebo in randomized controlled trials, but pain relief remains inadequate for most patients. ${ }^{62}$ Generally, in clinical trials, treatment is considered successful if patients would obtain $50 \%$ of reduction in the pain level associated with some additional beneficial effects on sleep, fatigue, depression and quality of life. ${ }^{63,64}$ Thus, the management of this condition basically consists of excluding other causes of painful peripheral neuropathy, improving glycemic control as a prophylactic therapy and using medications to alleviate pain. ${ }^{65}$ Despite of multimodal and multidisciplinary approaches to the treatment, the primary pathway is pharmacologically based. ${ }^{66}$ Three different agents have regulatory approval for the treatment of DNP: pregabalin, duloxetine and tapentadol. ${ }^{13,67}$ However, as pain relief is still suboptimal and challenging for clinicians ${ }^{68}$, drugs from various pharmacological classes have been used and some of them are included in this review (Table II). 
Antidepressants Neurologic pathways implicated in mood disorders share neurotransmitters with pathways associated with pain processing. ${ }^{69}$ It is therefore not surprising that there is a dual utility in alleviating neuropathic pain.

Tricyclic antidepressants The precise mechanism of action of Tricyclic antidepressants (TCAs) in analgesic efficacy is unclear, but they are thought to indirectly modulate the opioid system in the brain via serotonergic and norepinephrine nuro modulation, among other properties. ${ }^{70}$ TCAs require up-titration to effective doses, often over a period of 6 to 8 weeks before reasonable effects are noted; hence, compliance may sometimes be compromised. ${ }^{71}$ A meta-analysis by Rudroju et al. ${ }^{72}$ concluded that amitriptyline was the least effective but a well-tolerated agent compared to other antidepressant agents used to treat painful DPN. The 2017 position statement from the ADA stated that, although effective for the treatment of neuropathic pain, TCAs should be used with caution given their higher-risk profile, particularly in elderly populations. ${ }^{38}$

\section{Serotonin-norepinephrine reuptake inhibitors}

Two serotonin-norepinephrine reuptake inhibitors are used in painful DPN, duloxetine and, to a lesser extent, venlafaxine, which does not have FDA approval for use in the treatment of painful DPN. A third serotonin-norepinephrine reuptake inhibitor is des-venlafaxine, which was evaluated in a single randomized, controlled trial and showed some efficacy. ${ }^{73}$ These drugs primarily exert their effect via inhibiting serotonin and norepinephrine reuptake, resulting in the excitation of inhibitory descending path ways with alleviation of neuropathicpain. ${ }^{74}$ Duloxetine at both $40 \mathrm{mg}$ and $60 \mathrm{mg}$ has shown efficacy in treating painful DPN. ${ }^{75}$ Tanenberg et al. ${ }^{76}$ showed that duloxetine was non inferior to pregabalin in treating painful DPN in patients exhibiting an inadequate response to gabapentin. Duloxetine has a superior safety profile compared to amitriptyline, owing to the comparably lower rates of anti cholinergic side effects. Venlafaxine showed efficacy in treating painful DPN in a double-blind placebo controlled trial in which pain-intensity visual analog scale (VAS) scores were used as the primary outcome measure. ${ }^{77}$ Venlafaxine has shown superiority to duloxetine in some studies; however, there is a lack of larger-scale trials showing this effect. Additionally, it is important to note that venlafaxine must be slowly weaned to reduce the potential for adverse events, and it has not been approved by the FDA for use in treating neuropathicpain. ${ }^{77}$

\section{Anticonvulsants}

Pregabalin was the first anticonvulsant to receive approval from the Food and Drug Administration (FDA) for the treatment of postherpetic neuralgia, DNP and neuropathic pain after spinal cord injury. ${ }^{78-80}$ Pregabalin is a GABA analogue that selectively binds to pre-synaptic voltage-gated calcium channels containing the $\alpha 2 \delta 1$ subunit in the brain and spinal cord, causing inhibition of the release of excitatory neurotransmitters. ${ }^{81,82}$ Moreover, $\alpha 2 \delta 1$ subunits are responsible for increasing the functional expression of these channels, as a consequence of increased trafficking. Thus, the analgesic impaired trafficking of $\alpha 2 \delta 1$ subunit with a consequent diminished expression of functional calcium channels. ${ }^{83}$ Several clinical trials evaluating pregabalin in DNP showed efficacy in the management of this condition with a number needed to treat (NNT) of 6.3.7,64,84 In addition to its analgesic effects, pregabalin presents anxiolytic activity and it has a beneficial effect on sleep and quality of life, contributing, therefore, to improve the general condition of the patients. 82,84 The side effects include dizziness, somnolence, peripheral edema, headache and weight gain.? Some guidelines have also recommended gabapentin to treat DNP. ${ }^{85}$ Gabapentin and pregabalin have a similar mechanism of action and the first is licensed for neuropathic pain in the United Kingdom, but not in the United States. ${ }^{67}$ Some clinical trials have suggested that gabapentin and pregabalin present better analgesic efficacy than tricyclic antidepressants or opioids and other important aspects of these drugs include their tolerability and lack of serious toxicity. ${ }^{86}$ 


\section{Other anticonvulsants}

The use of topiramate has been evaluated in several placebo-controlled trials, with differing results. Raskin et al. ${ }^{87}$ randomized 323 subjects to topiramate versus placebo and found a significant $30 \%$ reduction in pain VAS scores with topiramate. A recent smaller study from Iran showed that gabapentin and topiramate equally reduced pain scores. ${ }^{88}$ Lamotrigine is chemically unrelated to other anti-epileptic agents. It is thought to exert its anti epileptic effect via sodium channels. Lamotrigine has been assessed in painful DPN. Eisenberg et al. ${ }^{89}$ observed a significant reduction in the numeric pain scale in $83 \%$ of patients randomized to lamotrigine compared to $73 \%$ receiving placebo, but this study was relatively small-scale $(n=59)$. In an analysis of data from 2 randomized trials, lamotrigine (300 and $400 \mathrm{mg}$ daily) showed inconsistent effects in DPN, and while it was well tolerated ${ }^{90}$, it cannot be advocated for use in painful DPN. ${ }^{91} \mathrm{~A}$ double-blind, placebo-controlled trial of lacosamide found it to be efficacious compared to placebo; however, the cohort receiving $600 \mathrm{mg}$ daily had a much higher withdrawal rate due to adverse reactions, such as nausea, tremor, headache, andfatigue. ${ }^{92}$

Table II: Current guidelines for painful diabetic peripheral neuropathy

\begin{tabular}{|c|c|c|c|c|c|}
\hline $\begin{array}{l}\text { Line of } \\
\text { Treatment }\end{array}$ & EFNS (2010) & AAN (2011) & NICE (2013) & AACE $(2015)^{96}$ & ADA $(2017)^{38}$ \\
\hline \multirow[t]{6}{*}{ 1st line } & Amitriptyline & Pregabalin & Amitriptyline & Amitriptyline & Duloxetine \\
\hline & Duloxetine & & Duloxetine & SNRI & Pregabalin \\
\hline & Pregabalin & & Pregabalin & Pregabalin & \\
\hline & Venlafaxine & & Gabapentin & Gabapentin & \\
\hline & Sodium valproate & & & Clonidine & \\
\hline & Gabapentin & & & & \\
\hline \multirow[t]{9}{*}{ 2nd line } & Tramadol & Amitriptyline & Amitriptyline & Tramadol & TCA \\
\hline & Opioids & Duloxetine & Duloxetine & Tapentadol & Gabapentin \\
\hline & & Sodium & Pregabalin & Topiramate & \\
\hline & & Valproate & Gabapentin & Oxcarbazepine & \\
\hline & & Venlafaxine & & Lidocaine $5 \%$ & \\
\hline & & Gabapentin & & Capsaicin & \\
\hline & & Tramadol & & & \\
\hline & & Opioids & & & \\
\hline & & Capsaicin & & & \\
\hline \multirow[t]{2}{*}{ 3rd line } & & & Capsaicin & & \\
\hline & & & Tramadol & & \\
\hline
\end{tabular}

AACE: American Association of Clinical Endocrinologists; AAN: American Academy of Neurology; ADA: American Diabetes Association; EFNS: European Federation of Neurological Societies; NICE: National Institute of Clinical Excellence (UK); SNRI: serotonin norepinephrine reuptake inhibitor; TCA: tricyclic antidepressant.

\section{Opioid analgesia}

Opioids are recommended to be used as second or third line treatment for DNP.7,97 One multicenter, randomized, placebo-controlled study reported the tramadol effectiveness to significantly improve scores on physical and social functioning ratings in patients with DNP, but beneath some side effects such as nausea, constipation, headache and somnolence. ${ }^{98}$ Morphine was also shown to be effective in reducing mean daily pain scores related to diabetic neuropathy and post herpetic neuralgia. ${ }^{99}$ Moreover, results of clinical trials indicated that diabetic neuropathic patients experienced a significant reduction in pain intensity and an improvement on quality of life during oxycodone treatment, compared to placebo-exposedgroup. ${ }^{100}$ Besides, oxycodone improved gabapentin but not the pregabalin effectiveness in promoting DNPrelief. 101 There is also evidence that the anti-hyper algesic effect of opioids is improved by the association with some drugs, such as the antidepressants amitriptyline, moclobemide and reboxetine. ${ }^{102}$ Tapentadol has been shown to be effective in the management of different types of chronic pain, including osteoarthritis knee pain, low back pain and DNP, with a tolerable safety profile. ${ }^{103}$ Specifically concerning DNP, a randomized-withdrawal, placebo-controlled trial reported reduction of at least $30 \%$ in pain intensity in about $50 \%$ of the patients that received tapentadol. ${ }^{104}$ Similar data were obtained in a recent clinical trial in diabetic neuropathic patients with moderate to severe pain, which experienced nausea $(21.1 \%)$ and vomiting $(12.7 \%)$ as side effects. ${ }^{105}$

\section{Others agents}

The drugs discussed below are currently associated to the pharmacological treatments already described according to the patients' symptoms and needs in order to achieve better relief of pain in DNP conditions. However, further studies are necessary, specially controlled clinical trials, to determine the more efficacious, safe and successful combinations to be applied in the management of DNP. ${ }^{99}$ 


\section{Topical medications}

Topical treatments for painful DPN may be particularly useful for patients not tolerating conventional systemic therapies, as there is a reduced prevalence of adverse effects. ${ }^{106}$ Furthermore, the risk for drug-drug interactions is also significantly reduced, making topical therapies more attractive for a growing number of patients with multiple co morbidities and poly pharmacy.

Capsaicin is a naturally occurring alkaloid found in red chili peppers. It works by selectively agonizing the transient receptor potential vanilloid 1 (TRPV1) receptor, which is expressed on small nerve fibers. Downstream signals from the TRPV1 receptor result in the release of substance $P$ and its subsequent depletion, which causes a reduction of painful stimuli conveyed to the CNS.107 The Capsaicin Study Group conducted a double-blind, placebo-controlled trial $(n=277)$ of $0.0075 \%$ topical capsaicin and found a significant reduction in pain, as measured by physicians' global evaluation and a VAS scale. ${ }^{108}$ Capsaicin is currently recommended as third-line therapy in the United Kingdom's National Institute of Clinical Excellence guidelines and second-line by the American Academy of Neurology for the treatment of neuropathic pain. Its use is severely limited by the frequency of application (4 times daily) and burning pain frequently induced on application. Of concern, capsaicin has been shown to lead to a reduction in thermal nociception and total denervation, with a putative increased risk for diabetic foot ulceration, and is not recommended in the treatment of painful DPN. ${ }^{109}$

Lidocaine plaster $5 \%$ applied for $18 \mathrm{~h} / \mathrm{d}$ has been shown to effectively provide relief in painful DPN and has been extensively used in post herpetic neuralgia. IV lidocaine has been used in the treatment of pain produced by nerve injury for many years. Major Gordon of the Royal Canadian Army Medical Corps used IV procaine to successfully provide analgesia to burn patients as early as $1943 .{ }^{91}$ A systematic review of data from 38 studies found a significant pain reduction using the $5 \%$ lidocaine patch that was comparable to those with amitriptyline, capsaicin, gabapentin, and pregabalin. ${ }^{106}$ The lidocaine patch was also found to be associated with fewer and less clinically significant side effects compared to systemic agents. ${ }^{106}$ Topical isosorbide di nitrate has been evaluated in the treatment of painful DPN. Impaired nitric oxide synthesis has been found to play a role in DPN pathogenesis. The vasodilatory response to nitroglycerin directly releases nitric oxide, suggesting a potential role for its use in patients with DPN. ${ }^{101}$ Topical lidocaine and glyceryl-trinitrate patches may be used in combination to provide 24 -hour pain cover with alternating 12-hour applications of each therapy.

Alpha lipoic acid - The benefit provided by alphalipoic acid (ALA) in the treatment of DNP possibly is due to its direct effects on the neuropathy, by reducing the oxidative stress, which has been defined as an important factor in the pathophysiology of the diabetic neuropathy. ${ }^{62}$ Its antioxidant and anti-inflammatory actions may contribute to an all-round improvement of diabetic neuropathy symptoms. ${ }^{84}$ In some clinical trials that evaluated ALA effect in diabetic patients, pain was not a primary end point. However, they have shown a moderate benefit in terms of pain reduction. ${ }^{82}$ In a randomized double-blinded trial, ALA-treated patients reported a greater reduction in neuropathic pain when compared to placebo-treated subjects. ${ }^{62}$ Compared to several drugs currently in use for DNP treatment, ALA has fewer side effects ${ }^{110}$, being nausea and vomiting the most common. ${ }^{82}$

Conclusion: Painful DPN presents a tremendous challenge to the health care system as prevalence of diabetes continues to grow exponentially. DPN accounts for considerable morbidity and mortality and reduced quality of life. Clinical recognition is required for allowing timely symptomatic management to reduce the morbidity associated with this condition. Future studies need to identify specific diagnostic criteria for DPN, include outcome measures that have been validated and are responsive to change, and consider the confounding influence of pharmacological management to the effect of exercise. Glycemic control is the central component of treatment, but it is difficult to achieve for many patients. The management of pain remains the key aspect of symptom treatment for DPN. 


\section{References}

1. International Diabetes Federation. IDF Diabetes Atlas. 8th ed. Brussels, Belgium: International Diabetes Federation; 2017.

2. Thibault V, Belanger M, LeBlanc E, Babin L, Halpine S, Greene B, et al. Factors that Could Explain the Increasing Prevalence of Type 2 Diabetes among Adults in a Canadian Province: a Critical Review and Analysis. Diabetology \& Metabolic Syndrome. 2016;8:71.

3. Albers JW, Pop-Busui R. Diabetic Neuropathy: Mechanisms, Emerging Treatments, and Subtypes. Curr Neurol Neurosci Rep. 2014;14:473.

4. Young MJ, Boulton AJ, MacLeod AF, Williams DR, Sonksen PH. A Multicentre Study of the Prevalence of Diabetic Peripheral Neuropathy in the United Kingdom Hospital Clinic Population. Diabetologia. 1993;36(2):150-54.

5. Alleman CJM, Westerhout KY, Hensen M, Chambers C, Stoker M, Long S, et al. Humanistic and Economic Burden of Painful Diabetic Peripheral Neuropathy in Europe: a Review of the Literature. Diabetes Res Clin Pract. 2015;109(2):215-25.

6. Pop-Busui R, Evans GW, Gerstein HC, Fonseca V, Fleg JL, Hoogwerf BJ, et al. Effects of Cardiac Autonomic Dysfunction on Mortality Risk in the Action to Control Cardiovascular Risk in Diabetes (ACCORD) Trial. Diabetes Care. 2010;33:1578-84.

7. Tesfaye S, Boulton AJ, Dickenson AH. Mechanisms and Management of Diabetic Painful Distal Symmetrical Polyneuropathy. Diabetes Care. 2013;36:2456-65.

8. Boulton AJ, Kirsner RS, Vileikyte L. Clinical Practice. Neuropathic Diabetic Foot Ulcers. N Engl J Med. 2004;351:48-55

9. Tesfaye S, Chaturvedi N, Eaton SE, Ward JD, Manes $\mathrm{C}$, Ionescu-Tirgoviste $\mathrm{C}$, et al. Vascular Risk Factors and Diabetic Neuropathy. N Engl J Med. 2005;352:341-50.

10. Low PA, Dotson RM. Symptomatic Treatment of Painful Neuropathy. JAMA. 1998;280:1863-64.

11. Quattrini C, Tesfaye S. Understanding the Impact of Painful Diabetic Neuropathy. Diabetes Metab Res Rev. 2003;19 Suppl 1:S2-S8.

12. Gore M, Brandenburg NA, Dukes E, Hoffman DL, Tai KS, Stacey B. Pain Severity in Diabetic Peripheral Neuropathy Is Associated with Patient Functioning, Symptom Levels of Anxiety and Depression, and Sleep. J Pain Symptom Manage. 2005;30:374-85.
13. Freeman R. New and Developing Drugs for the Treatment of Neuropathic Pain in Diabetes. Curr Diab Rep. 2013;13:500-508.

14. Javed S, Alam U, Malik RA. Treating Diabetic Neuropathy: Present Strategies and Emerging Solutions. The Review of Diabetic Studies: RDS. 2015;12:63-83.

15. Stino AM, Smith AG. Peripheral Neuropathy in Prediabetes and the Metabolic Syndrome. J Diabetes Investig. 2017;8:646-55.

16. Dyck PJ, Kratz KM, Karnes JL, Litchy WJ, Klein R, Pach JM, et al. The Prevalence by Staged Severity of Various Types of Diabetic Neuropathy, Retinopathy, and Nephropathy in a Population-Based Cohort: The Rochester Diabetic Neuropathy Study. Neurology. 1993;43:817-24.

17. Franklin GM, Kahn LB, Baxter J, Marshall JA, Hamman RF. Sensory Neuropathy in Non-Insulin-Dependent Diabetes Mellitus. The San Luis Valley Diabetes Study. Am J Epidemiol. 1990;131:633-43.

18. Abbott CA, Malik RA, van Ross ERE, Kulkarni J, Boulton AJM. Prevalence and Characteristics of Painful Diabetic Neuropathy in a Large Community-Based Diabetic Population in the U.K. Diabetes Care. 2011;34:2220-24.

19. Diabetes Control and Complications Trial Research Group. Nathan DM, Genuth S, Lachin J, Cleary P, Crofford O, Davis M, et al. The Effect of Intensive Treatment of Diabetes on the Development and Progression of Long-Term Complications in Insulin-Dependent Diabetes Mellitus. N Engl J Med. 1993:977-86.

20. Tesfaye S, Chaturvedi N, Eaton SEM, Ward JD, Manes $\mathrm{C}$, Ionescu-Tirgoviste $\mathrm{C}$, et al. for the EURODIAB Prospective Complications Study Group. Vascular Risk Factors and Diabetic Neuropathy. N Engl J Med. 2005; 352:341-50.

21. Martin CL, Albers JW, Pop-Busui R, DCCT/EDIC Research Group. Neuropathy and Related Findings in the Diabetes Control and Complications Trial/Epidemiology of Diabetes Interventions and Complications Study. Diabetes Care. 2014;37:31-38.

22. Sorensen L, Molyneaux L, Yue DK. The Relationship among Pain, Sensory Loss, and Small Nerve Fibers in Diabetes. Diabetes Care. 2006;29:883-87 
23. Young RJ, Zhou YQ, Rodriguez E, Prescott RJ, Ewing DJ, Clarke BF. Variable Relationship between Peripheral Somatic and Autonomic Neuropathy in Patients with Different Syndromes of Diabetic Polyneuropathy. Diabetes. 1986;35:192-97.

24. Morales-Vidal S, Morgan C, McCoyd M, Hornik A. Diabetic Peripheral Neuropathy and the Management of Diabetic Peripheral Neuropathic Pain. Post grad Med. 2012;124:145-53.

25. Chen YW, Hsieh PL, Chen YC, Hung CH, Cheng JT. Physical Exercise Induces Excess Hsp72 Expression and Delays the Development of Hyperalgesia and Allodynia in Painful Diabetic Neuropathy Rats. Anesth Analg. 2013;116:482-90.

26. Mendell JR, Sahenk Z. Clinical Practice. Painful Sensory Neuropathy. N Engl J Med. 2003;348:1243-55.

27. Eaton SE, Harris ND, Ibrahim S, Patel KA, Selmi F, Radatz M, et al. Increased Sural Nerve Epineurial Blood Flow in Human Subjects with Painful Diabetic Neuropathy. Diabetologia. 2003;46:934-39.

28. Fischer TZ, Waxman SG. Neuropathic Pain in Diabetes-Evidence for a Central Mechanism. Nat Rev Neurol. 2010;6:462-66.

29. Selvarajah D, Wilkinson ID, Gandhi R, Griffiths PD, Tesfaye S. Microvascular Perfusion Abnormalities of the Thalamus in Painful but Not Painless Diabetic Polyneuropathy: A Clue to the Pathogenesis of Pain in Type 1 Diabetes. Diabetes Care. 2011;34:718-20.

30. Torrance N, Elliott AM, Lee AJ, Smith BH. Severe Chronic Pain Is Associated with Increased 10 Year Mortality. A Cohort Record Linkage Study. Eur J Pain. 2010;14:380-86.

31. Galer BS, Gianas A, Jensen MP. Painful Diabetic Polyneuropathy: Epidemiology, Pain Description, and Quality of Life. Diabetes Res Clin Pract. 2000;47:123-28.

32. Spallone V, Greco C. Painful and Painless Diabetic Neuropathy: One Disease or Two? Curr Diab Rep. 2013;13(4):533-49.

33. Hartemann A, Attal N, Bouhassira D, Dumont I, Gin $\mathrm{H}$, Jeanne S, et al. Painful Diabetic Neuropathy: Diagnosis and Management. Diabetes Metab. 2011;37:377-88.

34. Ziegler D. Painful Diabetic Neuropathy: Advantage of Novel Drugs over Old Drugs? Diabetes Care. 2009;32 Suppl:S414-19.

35. Davies M, Brophy S, Williams R, Taylor A. The Prevalence, Severity, and Impact of Painful Diabetic Peripheral Neuropathy in Type 2 Diabetes. Diabetes Care. 2006;29:1518-22.
36. Lalli P, Chan A, Garven A, Midha N, Chan C, Brady $\mathrm{S}$, et al. Increased Gait Variability in Diabetes Mellitus Patients with Neuropathic Pain. J Diabetes Complications. 2013;27:248-54.

37. Yoo M, Sharma N, Pansoor M, Kluding PM. Painful Diabetic Peripheral Neuropathy: Presentations, Mechanisms, and Exercise Therapy. J Diabetes Metab. 2013;30(10):005.

38. Pop-Busui R, Boulton AJM, Feldman EL, Bril V, Freeman R, Malik RA, et al. Diabetic Neuropathy: A Position Statement by the American Diabetes Association. Diabetes Care. 2017;40:136-54.

39. Rajabally YA, Stettner M, Kieseier BC, Hartung HP, Malik RA. CIDP and Other Inflammatory Neuropathies in Diabetes - Diagnosis and Management. Nature Reviews Neurology. 2017;13:599-611.

40. Melzack R. The short - form Mcgill Pain Questionnaire. Pain. 1987;30:191-97.

41. Ziegler D, Rathmann W, Dickhaus T, Meisinger C, Mielck A. Neuropathic Pain in Diabetes, Prediabetes and Normal Glucose Tolerance: the MONICA/KORA Augsburg Surveys S2 and S3. Pain Medicine. 2009;10:393-400.

42. Tesfaye S, Boulton AJM, Dyck PJ, Freeman R, Horowitz M, Kempler $\mathrm{P}$, et al. Diabetic Neuropathies: Up Date on Definitions, Diagnostic Criteria, Estimation of Severity, and Treatments. Diabetes Care. 2010;33:2285-93.

43. Abbott C, Carrington A, Ashe H, Bath S, Every LC, Griffiths J, et al. The North West Diabetes Foot Care Study: Incidence of, and Risk Factors for, New Diabetic Foot Ulceration in a Community - Based Patient Cohort. Diabetic Medicine. 2002;19:377-84.

44. Wang F, Zhang J, Yu J, Liu S, Zhang R, Ma X, et al. Diagnostic Accuracy of Monofilament Tests for Detecting Diabetic Peripheral Neuropathy: A Systematic Review and Meta-Analysis. J Diabetes Res. 2017;2017:8787261.

45. Brown JJ, Pribesh SL, BasketteKG, Vinik AI, Colberg SR. A Comparison of Screening Tools for the Early Detection of Peripheral Neuropathy in Adults with and without Type 2 Diabetes. J Diabetes Research. 2017;2017:1467213.

46. Terkelsen AJ, Karlsson P, Lauria G, Freeman R, Finnerup NB, Jensen TS. The Diagnostic Challenge of Small Fibre Neuropathy: Clinical Presentations, Evaluations, and Causes. The Lancet Neurology. 2017;16(11):934-44 
47. Boyle J, Eriksson ME, Gribble L, Gouni R, Johnsen S, Coppini DV, et al. Randomized, Placebo-Controlled Comparison of Amitriptyline, Duloxetine, and Pregabalin in Patients with Chronic Diabetic Peripheral Neuropathic Pain: Impact on Pain, Polysomnographic Sleep, Daytime Functioning, and Quality of Life. Diabetes Care. 2012;35:2451-58.

48. Knowler WC, Barrett-Connor E, Fowler SE, Hamman RF, Lachin JM, Walker EA, et al.; Diabetes, Prevention Program Research Group. Reduction in the Incidence of Type 2 Diabetes with Lifestyle Intervention or Metformin. N Engl J Med. 2002;346:393-403.

49. Smith AG, Russell J, Feldman EL, Goldstein J, Peltier A, Smith S, et al. Lifestyle Intervention for Pre-Diabetic Neuropathy. Diabetes Care. 2006; 29(6):1294-99.

50. Kawanami D, Matoba K, Sango K, Utsunomiya K. Incretin-Based Therapies for Diabetic Complications: Basic Mechanisms and Clinical Evidence. Int J Mol Sci. 2016;17:1223-39.

51. Jaiswal M, Martin CL, Brown MB, Callaghan B, Albers JW, Feldman EL, et al. Effects of Exenatide on Measures of Diabetic Neuropathy in Subjects with Type 2 Diabetes: Results from an 18-Month Proof-of-Concept Open-Label Randomized Study. J Diabetes Complications. 2015;29(8):1287-94.

52. Sheng B, Truong K, Spitler H, Zhang L, Tong X, Chen L. The Long-Term Effects of Bariatric Surgery on Type 2 Diabetes Remission, Microvascular and Macrovascular Complications, and Mortality: A Systematic Review and Meta-Analysis. Obes Surg. 2017;27(10):2724-32.

53. Siahmansur TJ, Liu Y, Azmi S, Ferdousi M, Pemberton $\mathrm{P}$, Adam S, et al. Improvement in Small Fibre Neuropathy and Inflammatory Biomarkers after Bariatric Surgery. Atherosclerosis. 2016; 255:8-9.

54. Cohen R, Pechy F, Petry T, Correa JL, Caravatto PP, Tzanno-Martins C. Bariatric and Metabolic Surgery and Microvascular Complications of Type 2 Diabetes Mellitus. Brazilian Journal of Nephrology. 2015;37(3):399-409.

55. Kim HJ, Jung TS, Jung JH, Kim SK, Lee SM, Kim KY, et al. Improvement of Glycemic Control after Re-Emphasis of Lifestyle Modification in Type 2 Diabetic Patients Reluctant to Additional Medication. Yonsei Med J. 2013;54:345-51.

56. Umpierre D, Ribeiro PA, Kramer CK, Leitão CB, Zucatti AT, Azevedo MJ, et al. Physical Activity
Advice Only or Structured Exercise Training and Association with Hbalc Levels in Type 2 Diabetes: A Systematic Review and Meta-Analysis. JAMA. 2011;305(17):1790-99.

57. Maiorana A, O’Driscoll G, Goodman C, Taylor R, Green D. Combined Aerobic and Resistance Exercise Improves Glycemic Control and Fitness in Type 2 Diabetes. Diabetes Res Clin Pract. 2002;56:115-23.

58. Boulé NG, Haddad E, Kenny GP, Wells GA, Sigal RJ. Effects of Exercise on Glycemic Control and Body Mass in Type 2 Diabetes Mellitus: A Meta-Analysis of Controlled Clinical Trials. JAMA. 2001;286:1218-27.

59. Roque FR, Hernanz R, Salaices M, Briones AM. Exercise Training and Cardiometabolic Diseases: Focus on the Vascular System. Curr Hypertens Rep. 2013;15:204-214.

60. Sparks LM, Johannsen NM, Church TS, Earnest CP, Moonen-Kornips E, Moro C, et al. Nine Months of Combined Training Improves Ex Vivo Skeletal Muscle Metabolism In Individuals with Type 2 Diabetes. J Clin Endocrinol Metab. 2013;98:1694-1702.

61. van der Heijden MM, van Dooren FE, Pop VJ, Pouwer F. Effects of Exercise Training on Quality of Life, Symptoms of Depression, Symptoms of Anxiety and Emotional Well-Being in Type 2 Diabetes Mellitus: A Systematic Review. Diabetologia. 2013;56:1210-25.

62. Singleton JR, Smith AG. The Diabetic Neuropathies: Practical and Rational Therapy. Semin Neurol. 2012;32:196-203.

63. Huizinga MM, Peltier A. Painful Diabetic Neuropathy: A Management-Centered Review. Clinical Diabetes. 2007;25:6-15.

64. Moore RA, Wiffen PJ, Derry S, Toelle T, Rice AS. Gabapentin for Chronic Neuropathic Pain and Fibromyalgia in Adults. Cochrane Database Syst Rev. 2014;4:CD007938.

65. Snedecor SJ, Sudharshan L, Cappelleri JC, Sadosky A, Mehta S, Botteman M. Systematic Review and Meta-Analysis of Pharmacological Therapies for Painful Diabetic Peripheral Neuropathy. Pain Pract. 2014;14:167-84.

66. Hurley RW, Lesley MR, Adams MC, Brummett CM, Wu CL. Pregabalin as a Treatment for Painful Diabetic Peripheral Neuropathy: A Meta-Analysis. Reg Anesth Pain Med. 2008;33:389-94. 
67. Peltier A, Goutman SA, Callaghan BC. Painful Diabetic Neuropathy. BMJ. 2014;348:g1799.

68. Aslam A, Singh J, Rajbhandari S. Pathogenesis of Painful Diabetic Neuropathy. Pain Res Treat. 2014;2014:412041.

69. Mika J, Zychowska M, Makuch W, Rojewska E, Przewlocka B. Neuronal and Immunological Basis of Action of Antidepressants in Chronic Pain Clinical and Experimental Studies. Pharmacological Reports. 2013;65:1611-21.

70. Botney M, Fields HL. Amitriptyline Potentiates Morphine Analgesia by a Direct Action on the Central Nervous System. Ann Neurol. 1983;13:160-64.

71. Dworkin RH, O'Connor AB, BackonjaM, Farrar JT, Finnerup NB, Jensen TS, et al. Pharmacologic Management of Neuropathic Pain: Evidence-Based Recommendations. Pain. 2007;132:237-51.

72. Rudroju N, Bansal D, Talakokkula ST, Gudala K, Hota D, Bhansali A, et al. Comparative Efficacy and Safety of Six Antidepressants and Anticonvulsants in Painful Diabetic Neuropathy: A Network Meta-Analysis. Pain Physician. 2013;16:E705-E714

73. Allen R, Sharma U, Barlas S. Clinical Experience with Desvenlafaxine in Treatment of Pain Associated with Diabetic Peripheral Neuropathy. J Pain Res. 2014;7:339-51.

74. Hossain SM, Hussain SM, Ekram AR. Duloxetine in Painful Diabetic Neuropathy: A Systematic Review. Clin J Pain. 2016;32:1005-10.

75. Skljarevski V, Frakes EP, Sagman D, Lipsius S, Heinloth AN, Tentori HJD. Review of Efficacy and Safety of Duloxetine 40 to $60 \mathrm{mg}$ Once Daily in Patients with Diabetic Peripheral Neuropathic Pain. Pain Res Treat. 2012;2012:898347.

76. Tanenberg RJ, Irving GA, Risser RC, Ahl J, Robinson MJ, Skljarevski V, et al. Duloxetine, Pregabalin, and Duloxetine Plus Gabapentin for Diabetic Peripheral Neuropathic Pain Management in Patients with Inadequate Pain Response to Gabapentin: An Open-Label, Randomized, Noninferiority Comparison. Mayo Clin Proc. 2011;86:615-26.

77. Rowbotham MC, Goli V, Kunz NR, Lei D. Venlafaxine Extended Release in the Treatment of Painful Diabetic Neuropathy: A Double-Blind, Placebo-Controlled Study. Pain. 2004;110:697-706.

78. Verma V, Singh N, Singh JA. Pregabalin in Neuropathic Pain: Evidences and Possible Mechanisms. Curr Neuropharmacol. 2014;12:44-56.
79. Blommel ML, Blommel AL. Pregabalin: An Antiepileptic Agent Useful for Neuropathic Pain. Am J Health Syst Pharm. 2007;64:1475-82.

80. Guy S, Mehta S, Leff L, Teasell R, Loh E. Anticonvulsant Medication Use for the Management of Pain Following Spinal Cord Injury: Systematic Review and Effectiveness Analysis. Spinal Cord. 2014;52:89-96.

81. Peltier A, Goutman SA, Callaghan BC. Painful Diabetic Neuropathy. BMJ. 2014;348. 82. Zilliox L, Russell JW. Treatment of Diabetic Sensory Polyneuropathy. Curr Treat Options Neurol. 2011;13:143-59.

83. Stahl SM, Porreca F, Taylor CP, Cheung R, Thorpe AJ, Clair A. The Diverse Therapeutic Actions of Pregabalin: Is a Single Mechanism Responsible for Several Pharmacological Activities? Trends Pharmacol Sci. 2013;34:332-39.

84. Zychowska M, Rojewska E, Przewlocka B, Mika J. Mechanisms and Pharmacology of Diabetic Neuropathy - Experimental and Clinical Studies. Pharmacol Rep. 2013;65:1601-10.

85. Patel N, Mishra V, Patel P, Dikshit RK. A Study of the Use of Carbamazepine, Pregabalin and Alpha Lipoic Acid in Patients of Diabetic Neuropathy. J Diabetes Metab Disord. 2014;13:62.

86. Ziegler D, Schneider E, Boess FG, Berggren L, Birklein F. Impact of Comorbidities on Pharmacotherapy of Painful Diabetic Neuropathy in Clinical Practice. J Diabetes Complications. 2014;28:698-704.

87. Freeman R, Durso-Decruz E, Emir B. Efficacy, Safety, and Tolerability of Pregabalin Treatment for Painful Diabetic Peripheral Neuropathy: Findings from Seven Randomized, Controlled Trials across a Range of Doses. Diabetes Care. 2008;31:1448-54.

88. Nazarbaghi S, Amiri-Nikpour MR, Eghbal AF, Valizadeh R. Comparison of the Effect of Topiramate versus Gabapentin on Neuropathic Pain in Patients with Polyneuropathy: A Randomized Clinical Trial. Electron Physician. 2017;9:5617-22.

89. Wiffen PJ, Derry S, Lunn MP, Moore RA. Topiramate for Neuropathic Pain and Fibromyalgia in Adults. The Cochrane dDatabase of Systematic Reviews 2013;CD008314.

90. Vinik AI, Tuchman M, Safirstein B, Corder C, Kirby L, Wilks K, et al. Lamotrigine for Treatment of Pain Associated with Diabetic Neuropathy: Results of Two Randomized, Double-Blind, PlaceboControlled Sudies. Pain. 2007;128:169-79. 
91. Wiffen PJ, Derry S, Moore RA, Aldington D, Cole P, Rice ASC, et al. Antiepileptic Drugs for Neuropathic Pain and Fibromyalgia - an Overview of Cochrane Reviews. The Cochrane Database of Systematic Reviews. 2013;CD010567.

92. Shaibani A, Fares S, Selam JL, Arslanian A, Simpson J, Sen D, et al. Lacosamide in Painful Diabetic Neuropathy: An 18-Week Double-Blind Placebo-Controlled Trial. The Journal of Pain: Official Journal of the American Pain Society. 2009;10:818-28.

93. Attal N, Cruccu G, Baron R, Haanpaa M, Hansson P, Jensen TS, et al. EFNS Guidelines on the Pharmacological Treatment of Neuropathic Pain: 2010 Revision. European Journal of Neurology. 2010;17:1113-e88.

94. Bril V, England J, Franklin GM, Backonja M, Cohen J, Del Toro D, et al. American Academy of Neurology; American Association of Neuromuscular and Electrodiagnostic Medicine; American Academy of Physical Medicine and Rehabilitation. Evidence-Based Guideline: Treatment of Painful Diabetic Neuropathy [erratum in: Neurology. 2011; 77:603. Neurology. 2011;76:1758-65.

95. National Institute of Clinical Excellence (NICE). Neuropathic Pain in Adults: Pharmacological Management in Non-Specialist Settings. NICE; 2017.

96. Handelsman Y, Bloomgarden ZT, Grunberger G, etal. American Association of Clinical Endocrinologists and American College of Endocrinology. Clinical Practice Guidelines for Developing a Diabetes Mellitus Comprehensive Care Plan Executive Summary. Endocrine Practice. 2015;21:413-37.

97. Page N, Deluca J, Crowell K. Clinical Inquiry: What Medications Are Best for Diabetic Neuropathic Pain? J Fam Pract. 2012;61:691-93.

98. Harati Y, Gooch C, Swenson M, Edelman S, Greene D, Raskin P, et al. Double Blind Randomized Trial of Tramadol for the Treatment of the Pain of Diabetic Neuropathy. Neurology. 1998;50:1842-46.

99. Peltier A, Goutman SA, Callaghan BC. Painful Diabetic Neuropathy. BMJ. 2014;348:g1799.

100. Watson CP, Moulin D, Watt-Watson J, Gordon A, Eisenhoffer J. Controlled-Release Oxycodone Relieves Neuropathic Pain: A Randomized
Controlled Trial in Painful Diabetic Neuropathy. Pain. 2003;105:71-78.

101. Hanna M, O'Brien C, Wilson MC. Prolonged-Release Oxycodone Enhances the Effects of Existing Gabapentin Therapy in Painful Diabetic Neuropathy Patients. Eur J Pain. 2008;12:804-13.

102. Cegielska-Perun K, Bujalska-Zadrożny M, Gąsińska E, Makulska-Nowak HE. Enhancement of Antinociceptive Effect of Morphine by Antidepressants in Diabetic Neuropathic Pain Model. Pharmacol Rep. 2014;66:228-34.

103. Afilalo M, Morlion B. Efficacy of Tapentadol ER for Managing Moderate to Severe Chronic Pain. Pain Physician. 2013;16:27-40.

104. Schwartz S, Etropolski M, Shapiro DY, Okamoto A, Lange R, Haeussler J, et al. Safety and Efficacy of Tapentadol ER in Patients with Painful Diabetic Peripheral Neuropathy: Results of a Randomized-Withdrawal, Placebo-Controlled Trial. Curr Med Res Opin. 2011;27:151-62.

105. Vinik AI, Shapiro DY, Rauschkolb C, Lange B, Karcher K, Pennett D, Etropolski MS. A Randomized Withdrawal, Placebo-Controlled Study Evaluating the Efficacy and Tolerability of Tapentadol Extended Release in Patients with Chronic Painful Diabetic Peripheral Neuropathy. Diabetes Care. 2014;37:2302-09.

106. Wolff RF, Bala MM, Westwood M, Kessels AG, Kleijnen J. 5\% Lidocaine Medicated Plaster in Painful Diabetic Peripheral Neuropathy (DPN): A Systematic Review. Swiss Medical Weekly. 2010;140:297-306.

107. Markovits E, Gilhar A. Capsaicin - an Effective Topical Treatment in Pain. Int $\mathrm{J}$ Dermatol. 1997;36:401-404.

108. The Capsaicin Study Group. Treatment of Painful Diabetic Neuropathy with Topical Capsaicin: A Multicenter, Double-Blind, Vehicle-Controlled Study. Arch Intern Med. 1991;151:2225-29.

109. Polydefkis M, Hauer P, Sheth S, Sirdofsky M, Griffin JW, McArthur JC. The Time Course of Epidermal Nerve fibre Regeneration: Studies in Normal Controls and in People with Diabetes, with and without Neuropathy. Brain. 2004;127:1606-15.

110. Mijnhout GS, Alkhalaf A, Kleefstra N, Bilo HJ. Alpha Lipoic Acid: A New Treatment for Neuropathic Pain in Patients with Diabetes? Neth J Med. 2010;68:158-62. 